\title{
Apuntes iniciales hacia una metodología del sujeto estético para la formación universitaria
}

\author{
Preliminary notes towards a methodology of the \\ aesthetic self in the university education
}

FRANCESCO PANICO*

El objetivo de este artículo es proponer un bosquejo inicial de una metodología para la enseñanza universitaria denominada "la construcción estética del sujeto", inspirada en los recientes horizontes de la pedagogía constructivista en campo estético, cuyo fundamento teórico remite a los estudios sobre la epistemología de las artes. La metodología propuesta se basa en tres axiomas, que serán llevados a la práctica a través de la aplicación del género narrativo de la autoficción. El sujeto formativo, que es el intérprete y el resultado de esta práctica, es designado con el nombre genérico de "Yo narrativo". Este, sin embargo, no será objeto de profundización ulterior en este escrito, puesto que su tratamiento requiere un nivel ulterior de análisis.

The goal of this paper is to propose e preliminary sketch of a methodology for university education called "The construction of aesthetic self". It inspires by the recent perspectives of constructivist pedagogy in the specific field of the epistemology of art. This methodology is based on three axioms, which will be taken to the practice by the application of the narrative genre called "autofiction". The formative subject, which is the performer and, at the same time, the outcome of this practice, is designated by the generic name of "narrative self". This one, nevertheless, will not to be an item of subsequent developing in the

Palabras clave:

estética, educación universitaria, yo, autoría, autoficción

\author{
Keywords: \\ aesthetic, \\ university \\ education, \\ self, \\ authorship, \\ autofiction
}

Recibido: 10 de mayo de 2018. | Aceptado para su publicación: 27 de febrero de 2019. Recuperado de: https://sinectica.iteso.mx/index.php/SINECTICA/article/view/880 DOI: 10.31391/S2007-7033(2019)0052-008

\footnotetext{
* Doctor en Historia y Estudios Regionales por el Instituto de Investigaciones Histórico-Sociales de la Universidad Veracruzana. Posdoctorado en Historia Ambiental por el Centro de Investigaciones en Geografía Ambiental de la UNAM. Académico de tiempo completo de la Universidad Veracruzana. Líneas de investigación: territorialidad y poder en contextos rurales y mineros, y cosmología y territorialidad precolombina. Correo electrónico: panchop75@hotmail.com/ https://orcid.org/0000-0001-8883-9385
} 


\section{INTRODUCCIón}

T a mayoría de los planes de estudio universitarios, en una época como la actual dominada por una fuerte tendencia a la estandarización curricular en todos los países del hemisferio occidental (Meyer, Kamens y Benavot, 1992; Casassus, 2010), destacan la importancia de una especialización profesional acompañada por contenidos axiológicos transversales. La principal misión de la universidad, hoy en día, es ofrecer al alumnado una formación orientada, principalmente, por criterios de futura rentabilidad laboral, a la vez que los aspectos de orden ético y de responsabilidad social son tratados de forma marginal al incorporarse como lineamientos generales acerca de cómo un buen profesional puede ser, también, un buen ciudadano. Sin embargo, el acento sigue puesto, de manera contundente, sobre lo profesional, hecho que arrincona los temas de naturaleza ética, civil y psicológica, pese a todos los llamados a la integralidad de la formación, en una posición de evidente subordinación (Weller, 2003; Jacinto, 2004).

Es preciso señalar que no nos referimos aquí solo al hecho de que, en ciertas zonas del planeta (como en América Latina), la homogeneización curricular iniciada con los acuerdos de Bolonia, debido a las diferentes condiciones sociales, históricas y políticas de los países interesados, es objetivamente inactuable (Beneitone et al., 2007; Garay, 2008), sino que, aunque lo fuera, quedaría pendiente reflexionar sobre la cuestión de si es pertinente, en la universidad, insistir en la especialización profesional sin que esta sea acompañada por una formación cívica y psicológica a la altura de los retos, presentes y futuros, de la civilización.

Es evidente cómo el currículo universitario está hoy al servicio del mercado del trabajo; sin embargo, como señalan varios autores (Casalet, 2010; Pérez, 2012), la universidad es incapaz, en general, de ofrecer una formación oportuna para el futuro de sus estudiantes, puesto que su pesada estructura burocrática, junto con las resistencias que ella exhibe a menudo ante las directivas del mundo político y productivo, la hace, desde la perspectiva del estado y la empresa, una institución inviable tanto en lo formativo (a causa de su mal funcionamiento) como, y sobre todo, en lo económico y financiero (Acosta, 2008). En suma, para el mundo globalizado, aunque nadie se atreva a decirlo con claridad, la universidad se ha convertido en un peso muerto, en un gigante con pies de plomo, que no sabe cumplir con el cometido de la formación para el trabajo y que, por si fuera poco, gasta cuantiosos recursos públicos (De Vries y Álvarez, 2005).

Ante ese panorama un tanto sombrío, surge la pregunta de qué manera podemos brindar una educación universitaria que no solo sea capaz de contribuir a la inserción del individuo en el mundo profesional (por cierto, ya envilecido por un mercado del trabajo al que muy pocas personas logran incorporarse de manera coherente con sus estudios) (Camarena y Velarde, 2009), sino que lo ayude a constituirse como un sujeto integral, capaz de moverse de manera inteligente y responsable en un mundo competitivo y plural.

En este artículo, planteamos la emergencia de una praxis pedagógica que intente superar la separación tajante entre lo profesional y técnico, por un lado, y lo ético y psicológico, por el otro. La respuesta a esta aparente disyuntiva puede ser encon- 
trada en lo que aquí definimos como la "construcción del sujeto estético", a saber, una metodología que ayude al alumno a estructurar de manera coherente, y para él significativa, los diferentes contenidos formativos en el ámbito tanto del individuo como de la colectividad. Es importante precisar que no pretendemos delinear y describir con exactitud un nuevo método, ni menos indicar el modo de aplicarlo, sino solo sugerir algunas líneas teóricas que, con base en lo estético y en el horizonte de la autoficción, convergen hacia tres posibles axiomas. Será tarea de trabajos posteriores, debido a la extensión del tema, intentar definir con más detalle los posibles alcances de esa incipiente idea metodológica.

\section{LA DIMENSIÓN ESTÉTICA}

No ignoramos, desde luego, que al interior de la academia, sobre todo en los campos de la educación y la psicología, han existido propuestas muy originales para abordar el tema de cómo los contenidos formativos se estructuran y acomodan al interior del sujeto que los recibe y reorganiza (Restrepo, 1994; Cubero y Villanueva, 2014). Sin embargo, muy pocos son los que han tratado de hacerlo desde la estética (Rosenwald y Ochberg, 1992; De Garay, 2013), pues las artes y la belleza, en nuestra sociedad actual, son arrinconadas, lamentablemente, o al ámbito de lo prescindible, porque son juzgadas ilusorias, o, peor, al del entretenimiento (Rincón, 2006).

En la Grecia antigua, por ejemplo, la formación se concebía como algo inherente a la existencia, y los temas objeto de debate surgían de la vida real (Marrou, 2004). Ahí, en el mundo de los filósofos, no reinaba el mantra de la especialización, puesto que la juventud se formaba con el objetivo de que encontrase, con la ayuda de los educadores, la manera más adecuada para organizar el conocimiento con relación a su propio contexto de vida y a sus capacidades creativas; es decir, la adquisición del conocimiento se daba por conducto de un criterio de belleza (Nietzsche, 1963). La escuela, pues, en los términos en que hoy la conocemos no existía, ni tampoco había una diferencia concluyente entre las esferas de las humanidades y las artes, por un lado, y las de la técnica y las matemáticas, por el otro. La ciencia coincidía con el conocimiento; no con un método en especial (Beard y Henderson, 2016).

Esta breve digresión sobre los griegos no intenta celebrar una apología, de por sí anacrónica, de su mundo y su sistema educativo, sino subraya la importancia de un concepto: el valor de las artes en la formación del estudiante universitario. Ese valor, sin embargo, no tendrá validez solo en el orden del contenido, sino también y sobre todo en el de la forma (entendida, en sentido clásico, como arquitectura), porque es en el orden de la forma donde se adquieren los saberes que permanecen, a saber, las estructuras cognitivas que permiten organizar cualquier tipo de contenido particular (Cuesta, 1997). En últimos términos, es la forma, más que los contenidos, la que se encarga de brindar pleno sentido a la intrínseca dispersión de los contenidos particulares (Bateson, 1979).

El arte es mucho más que representación e identificación, es decir, es mucho más que una simple imitación de la vida (Lukács, 1982; Dewey, 2008). Los lectores corrientes estamos acostumbrados a pensar que ella, cuando mucho, es capaz de ofrecernos diversión, de hacernos reconocer en las situaciones representadas modelos de conducta comparables con los de nuestras vidas "verdaderas", pero eso 
significaría ver apenas una parte mínima del asunto. El arte es una postura ante la vida, una manera de existir. En pocas palabras, involucra una ética, solo que esta, a diferencia de lo que se pretende en la vida real, no se construye sobre fundamentos morales, sino estéticos. Nos preguntamos: ¿sería del todo descabellado pensar que el ser humano, en vez de conducirse por lo que es justo, lo hiciera también por lo que es bello? Es más: ¿en una sociedad tan individualista como la nuestra, no sería más efectiva la adopción de un criterio estético personal más que uno basado en una improbable ética colectiva?

Es obvio que el riesgo de pretender conducirse de manera exclusiva por lo bello y no por lo justo sería el de desacreditar los preceptos éticos y morales que rigen históricamente cualquier tipo de sociedad política. Pero aquí no nos referimos a un nuevo sadismo (aludimos, con esta palabra, al legado del Marqués de Sade, sin otra ulterior especificación) ni de un renovado individualismo desbordado y estetizante que no considerara la cuestión del derecho ajeno. Al contrario, hablamos de una acción guiada por un sentido de belleza y proporción, ambas consideradas por Aristóteles bases formales de la responsabilidad individual y social. De esa manera, se haría realidad lo que el estagirita afirmaba acerca de la equivalencia entre lo bueno y lo bello. Existe una estrecha relación, en suma, entre lo ético y lo estético (Castro, 2012), y es esta correspondencia, respecto a la formación universitaria, la que abordamos en este trabajo y para ello nos remitimos primero a un asunto que juzgamos fundamental: el de la autoría.

\section{LA AUTORÍA}

Si antes nos referimos en general al arte, ahora nos enfocaremos en uno en particular: la literatura. Ello por una simple razón: la construcción del sujeto estético pasa por los actos de la escritura y la lectura, en los que se plasma, al mismo tiempo, la estructura de la personalidad y la de la obra (Eco, 1981). Hasta cabría mencionar aquí la hipótesis de que la misma literatura haya nacido porque alguien, en un determinado momento de su vida, quiso liberarse de la pesada carga de aquello que sentía que lo aprisionaba. Platón, al imaginarse a su maestro Sócrates, ha sido quizá el primer "novelista" en crear un personaje que, a través de preguntas muy sencillas y acertadas, invitaba a su interlocutor a empeñarse en una búsqueda interior que lo llevara a enfrentarse con algunas verdades evidentes y, a menudo, incómodas.

Lo que Proust opinaba acerca del oficio de escribir a inicios del siglo XX, a saber, la escritura como actividad solitaria, que permite al escritor aligerarse del peso de la inautenticidad impuesta por las máscaras sociales, ya lo había realizado artísticamente, muchos siglos antes, otro autor, quien, por si fuera poco, admitía aborrecer todo lo que, como la poesía, olía a descarada mentira. En este sentido, la muy conocida técnica mayéutica de Sócrates vendría a ser el primer recurso literario puesto en boca de un personaje, es decir, de alguien que, en sí, ya es un invento, aunque uno, como la historia lo ha demostrado, no menos real que cualquiera de nosotros.

Estos ejemplos pretenden sugerir que el oficio de la escritura, no menos que el de la lectura, implican aspectos concretos, existenciales dirían algunos, que remiten al asunto de la autoría, es decir, de la creación y la forma (Foucault, 1999; Barthes, 1987). La construcción de nuestra personalidad podría ser un ejemplo de ello, puesto que, a lo largo de nuestras vidas, nos dedicamos a armar un rompecabezas de 
experiencias de todo tipo, cuyas piezas intentamos colocar con orden para que las cosas adquieran un sentido.

De esa manera, intentamos remedar las contradicciones y asperezas de un mundo en sí caótico, cuyo orden debemos descubrir (o inventar) nosotros. Siguiendo este sencillo razonamiento, todos somos, de alguna manera, autores, a saber, pequeños dictadores de un mundo ideado por nosotros. Autores de nuestras propias historias, las cuales, como en el caso de los literatos, a veces decidimos consignar a otro vacío, el de la página, como si ella fuese esta ausencia de sentido de la que hablábamos y la escritura la manera para negarla o, por lo menos, resistirse a ella.

No obstante, el problema de la autoría no se limita solo a quienes escriben, sino abarca el universo entero de la representación. El lector, a la par que el autor, es también un creador, es decir, un personaje quien no se rinde con tanta facilidad ante la autoría impuesta por otro y que, aunque no esté siempre consciente de ello, inicia el viaje que lo llevará a contar su propia historia. ¿No es esto lo que nos enseñaron, en términos muy escuetos, las grandes obras del pasado como Las mil y una noches, el Decamerón, Gargantúa y Pantagruel y el Quijote?

Cuando la literatura, como labor estética, se acerca a la dimensión ética de la construcción del sujeto a través de los oficios que le son propios (la escritura y la lectura), y no solo por conducto de sus contenidos particulares (diferentes en cada obra y cada autor), ella puede convertirse en un modo de encarar las inquietudes de nuestra atribulada civilización planetaria (Bárcena, 2016), la cual, desde hace varios siglos, se ha encaminado hacia una visión y construcción utilitarista tanto de los sujetos como de los objetos (Horkheimer, 1973). Esta ética utilitarista del hombre moderno choca en todo momento con su pretensión de ser moralmente otro, con ese mundo moral alternativo que él se construye (o que alguien le proporciona ya confeccionado) para no hacerse responsable de sus acciones; de ahí la esquizofrenia de nuestra sociedad y del hombre común que la habita, muy bien caracterizado y parodiado por los excéntricos personajes del director de cine (y escritor) Woody Allen.

Nuestra referencia al papel de la autoría procura acercar la literatura al debate actual sobre qué clase de marco contextual necesita el ser humano, y en particular el estudiante universitario, para aspirar a una vida social y profesional plena. ¿Qué sucedería, entonces, si los planes de estudio y los métodos de investigación, en vez de ser dominados por el criterio de la coherencia disciplinaria y por un corto sentido de objetividad, previeran el uso de principios estéticos? En el siguiente apartado abordaremos esta pregunta a partir de la reflexión sobre un género literario que, en los últimos años, ha atraído la atención de muchos especialistas: la autoficción.

\section{LA AUTOFICCIón}

La reflexión que proponemos atañe a la estructura del proceso de formación. Nuestra metodología, como hemos dicho, se apoya en un criterio estético, estructurador de los contenidos formativos particulares, los cuales, en el caso que nos concierne, se relacionan con la literatura y los saberes que hemos acumulado, por una u otra razón, a lo largo de nuestras vidas.

La autoficción (cuyo germen se encuentra en la autobiografía) se alimenta tanto

Panico. Apuntes iniciales hacia una metodología del sujeto estético para la formación universitaria Sinéctica 52 www.sinectica.iteso.mx 
de estos como de aquella, porque si, por un lado, nuestra memoria intenta consignarnos imágenes verdaderas de nuestro pasado según una secuencia coherente (acto que, de por sí, ya es una metaforización de la experiencia vivida), por el otro, en nuestro recuerdo (visto como una actualización de la memoria en el presente) las imágenes se confunden y se mezclan. Recordar, en suma, representa el primer escalón de la ficción. Durante este acto, lo real y lo imaginado ya no son distinguibles a ciencia cierta (Musitano, 2016). La literatura, en estos términos, proporciona imágenes y situaciones que completan y enriquecen las que nos pertenecen por haberlas vivido en nuestra piel. Por ello, la literatura es capaz de abonar tanto al conocimiento como a la formación personal del individuo, y más allá, alienta a que sea el propio sujeto quien coloque los elementos (vivenciales y cognitivos) que necesita alrededor de una arquitectura establecida por él.

La autoficción permite recuperar la dimensión personal de la experiencia y colocarla dentro de una trama que la engloba y la supera a la vez, sin que tenga mucha importancia, por lo que se ha dicho acerca de la memoria y el recuerdo, el hecho de que una situación sea real o imaginada. Los actos que ponen en marcha esta operación de construcción del self estético o narrativo son, en lo concreto, los de la escritura y la lectura.

Ahora bien, no cabe duda de que un principio formal esté en la base también de la arquitectura que rige la organización de los contenidos de cada disciplina particular, pero en las disciplinas clásicas este principio formal es externo, vinculado a una tradición académica que deja muy poca libertad al sujeto que investiga. Esta situación no ha sido corregida por las recientes perspectivas multidisciplinaria e interdisciplinaria (Morin, 2001). De ahí la urgencia de una metodología que, en vez de conducirse por principios disciplinarios externos al sujeto, ponga como su objetivo coadyuvarlo en la construcción de un conocimiento propio y situado (Latour, 2008). Sería esta, quizá, una manera de apostarle a una política social y educativa que no produzca profesionales estandarizados, sino que forme a personas con sentido de autonomía y capacidades dialógicas (García de la Sienra, 2015).

\section{HACIA LA CONSTRUCCIÓN DEL SUJETO ESTÉTICO}

El arte, debido a la importancia que otorga a la forma, podría considerarse, en el sentido que aquí planteamos, una verdadera metodología, tan válida para la ficción como para la realidad. En efecto, cuando intentamos explicar de manera objetiva el porqué de las cosas o la "esencia" de un objeto, descubrimos que apenas estamos contando historias, es decir, estamos creando una secuencia temporal en la que los hechos se acomodan, por cuanto parezca lógica su encadenación, de una manera del todo arbitraria (White, 1992; Ricoeur, 2007). En suma, los seres humanos no hacemos otra cosa que contar historias. ¿Por qué, entonces, no pensar en que la ficción nos pueda ayudar a encarar el complicado enredo de la vida? En pocas palabras, ¿por qué no hemos hecho del arte una metodología de conocimiento? Creo que nuestra incipiente reflexión acerca del sujeto estético represente un esfuerzo para sugerir una pedagogía centrada en el arte.

Esbocemos, pues, el escenario de esa posible metodología. Sus axiomas serían tres:

-La ética y la estética coinciden en el terreno de la forma. 
-La existencia y el conocimiento tienen un carácter dialógico.

-La realidad y la ficción son ámbitos especulares.

\section{La ética y la estética coinciden en el terreno de la forma}

Ya se ha dicho cómo, en el terreno de la forma, ética y estética coinciden: la vida sería una especie de novela, en la cual materiales existenciales heterogéneos se condensan alrededor de una personalidad. Asimismo, la literatura sería una suerte de vida en la que materiales ficcionales heterogéneos se condensan alrededor de una obra (Augé, 2003). Podemos escoger la definición que más nos agrade, pues ambas son válidas.

Si estos principios los aplicáramos al campo de la formación universitaria, las carreras, así como son hoy, carecerían de sentido, y solo habría una gran cantidad de cursos entre los cuales, con el apoyo de un tutor, el alumno elegiría algunos con base en sus propios intereses formativos, y se titularía con un trabajo que coincidiría con el relato de su proceso de aprendizaje durante los años de la universidad, pero como este panorama, por la situación actual, parece imposible, lo que sí podríamos hacer es organizar nuestras clases según principios estéticos para abonar, así, a aquella autonomía y a aquel conocimiento que todos, de manera indistinta de nuestra posición en la sociedad, poseemos (Faix, 2013).

Dicho principio de autonomía implicaría la colocación del docente en el borde de la dinámica de enseñanza-aprendizaje, que es, en cambio, la que tiene que ocupar el centro, de modo que todos se sitúen a la misma distancia con respecto a ella. Los contenidos serán descubiertos, seleccionados y trabajados durante la praxis, y no como elementos previos a la experiencia formativa. Así, el docente se convierte en una guía que promueve y que aprende, y deja de ser alguien que, de manera heterónoma, impone su forma y contenidos particulares, de modo que el conocimiento sea una suerte de historial de vida en el que distintas experiencias convergen para conformar el universo del saber del individuo que indaga (Bombini, 2009; Maturana y Varela, 2003).

Un conocimiento de esa clase dejaría de ser un ejercicio enfocado al discernimiento imparcial del objeto investigado, pero no en el sentido de que simplemente rescataría la importancia del sujeto, sino porque encontraría que sujeto y objeto comparten una naturaleza más discursiva que ontológica, puesto que todo lo vemos siempre desde un punto de vista particular, que es el de nuestra limitada capacidad perceptiva (Gombrich, Hochberg y Black, 2012).

Estos conceptos son superados por la realidad, en el marco de la cual descubrimos que ni somos dueños de nosotros mismos ni tampoco de la naturaleza, es decir, del mundo externo (Freud, 1976; Fourez, 2006). Por esta razón, consideramos a la literatura tan especial: por su carácter "democrático", si se quiere, ya que cada voz desempeña un papel en la definición del conjunto, porque cada una de ellas abona a la formación de la personalidad y a la aclaración de la existencia. En este punto convergen ética y estética: “... en Dostoievski el hombre no sólo se proyecta hacia el exterior, sino que por primera vez llega a ser lo que es” (Bajtín, 2012, p. 455).

En los personajes que pueblan la obra de este novelista ruso, el crítico de la literatura Mijaíl Bajtín (también ruso) ve un ejemplo de cómo la polifonía (la presencia de múltiples voces al interior de una unidad, sea esta representada por un individuo, 
un grupo o, incluso, una novela), más allá de figurar un categoría artística (usada tanto en música como en literatura), es una condición del ser, de modo que la persona termina siendo una extraña amalgama de consciente e inconsciente, de ficción y realidad, de colectividad e individualidad (Bajtín, 2005): en suma, de múltiples puntos de vista y materiales de vida, como si estuviéramos en presencia de una especie de cuadro cubista. Aquellos que opten por ofrecer un espacio de expresión a sus voces internas estarán también en posibilidad de aclararse a sí mismos, y hacer del arte una metodología de conocimiento.

De ese modo, le ética se desvincularía de cualquier imperativo categórico, es decir, de un sistema prescriptivo que decide de antemano la clase de conducta que deberá tener el sujeto en ciertas situaciones ideales. En vez de ser de naturaleza moral, la ética se edificaría sobre bases estéticas, en cuyo marco los valores de verdad se relativizan y abren, así, la jaula en la que todo sistema prescriptivo resguarda celosamente la elección.

Volviendo al asunto de la organización de la clase y de sus contenidos, será esencial el uso de un diario de aprendizaje (Brockbank y McGill, 2002) al que el alumno pueda confiar sus experiencias formativas, tanto científicas como no. Su organización alrededor de un núcleo de sentido dependerá de un criterio abierto, que sabe ajustarse, esto es, adaptarse y mediar las naturales dinámicas del tiempo.

\section{La existencia y el conocimiento tienen un carácter dialógico}

Como mencionamos, no somos siempre los mismos a lo largo de nuestra vida. A veces no lo somos ni siquiera de un minuto para otro. Nuestro Yo es un personaje escurridizo, extremadamente borroso, que nos induce a pensar que nuestra identidad siempre es única y definitiva (Ricoeur, 2006; Nietzsche, 1996; Agamben, 1988). En realidad, sabemos que, debido a nuestra humanidad, somos lo que todo el ser humano ha sido, es y será a lo largo de su existencia como especie. Incluso nos podemos reconocer, si aceptamos ir más allá de este argumento, en ciertas disposiciones de la vida biológica, e incluso inorgánica (Morin, 2010). Somos por naturaleza seres dialógicos, diría Bajtín, igual que las novelas.

Nuestras palabras, e incluso nuestras acciones, no nacen con nosotros, sino son el resultado del consolidarse, en el tiempo, de discursos y conductas extraindividuales. En suma, pese a que estamos hechos cada uno de nuestra propia carne, pertenecemos a un organismo mucho mayor, sin el cual nadie de nosotros existiría. Nuestra sociedad, a partir de la muerte de algunas certezas que considerábamos eternas y que guiaban el funcionamiento de nuestras anteriores experiencias civilizatorias, se ha vuelto monológica (Morin, 1988). Ella se ha sustituido a Dios, pero no ha logrado que el ser humano, en concomitancia con la masificación provocada por el sistema productivo dominante desde mediados del XIX, se emancipara, a saber, se volviera libre de la necesidad de recurrir a alguna norma o principio exterior para determinar su conducta.

Nuestra civilización aborrece la libertad porque ha abolido, por lo menos en su forma, aunque no en sus proclamas y consignas, el dialogismo, es decir, la capacidad que tenemos los seres humanos de reconocernos en el otro (Levinas, 1995; Bajtín, 
2012). No se trata aquí de encumbrar a norma suprema ningún altruismo piadoso, sino simple y llanamente acudir a un principio sin el cual cualquier sistema no sería tal, pues el flujo de información se difunde a través del conjunto, llevado por los elementos singulares que lo componen, como en cualquier organismo animado o inanimado (Morin, 1988). Por esta razón, aprender en colectividad nos ayuda a personalizar nuestro camino por conducto del espejo que nos ofrece el otro, pues sus experiencias también son las nuestras.

Así que el dialogismo no se prefigura como una necesidad ética ni menos como un imperativo moral, sino como la posibilidad por parte de la humanidad de plasmar su actual convivencia sobre la base de mecanismos observados en esferas más amplias que las que conciernen exclusivamente al hombre. La naturaleza, por ejemplo, desde que los enfoques adoptados en su estudio han hecho hincapié en lo ecosistémico, es decir, en la relación como base de entendimiento de los cambios y permanencias en el marco de la evolución, también funciona según principios dialógicos, aunque eso no significa que todo lo que ella crea también se conserva, sino que mantiene un amplio abanico de opciones para que el sistema se mantenga con vida. En pocas palabras, la naturaleza tiende a preservar sus voces para luego combinarlas de distintas maneras en la creación de los múltiples fenómenos que la constituyen (Gould, 1989).

La realidad, hemos afirmado (utilizando una metáfora musical que muy bien nos viene al caso), guarda un carácter polifónico, se asemeja a una gran orquesta cuyo director, sin embargo, no es nadie en particular. La naturaleza, para adquirir una estructura asequible a nuestros sentidos, no precisa de ninguna voluntad ordenadora que la gobierne, sino del libre juego de las voces que, pese a su singularidad e independencia, siempre terminan aglutinándose alrededor de un sentido, o sea, de una forma (Monod, 2016).

Por ello, es tan importante que los estudiantes universitarios (aunque esto, de hecho, es válido para todos) aprendan de situaciones concretas, puesto que de la observación de los fenómenos, sin que medie necesariamente método disciplinario alguno, siempre podrá vislumbrarse un principio formal que les subyace. También, la espontaneidad y la improvisación, a diferencia de lo que se cree, sin que nadie intervenga en ello de forma voluntaria y consciente, exhiben una idea de forma (Feynman, 2017). De ser así, el papel de la formación ya no consistiría en vaciar en la mente y el cuerpo del educando las estructuras formales pensadas por otros, sino de ayudarlo a que, de manera autónoma, reconozca en cada situación una arquitectura de base que dispone sus contenidos particulares según cierto orden.

La aportación del individuo consistirá, entonces, en montar sobre la apercepción de esta forma básica, una suya, conscientemente artificial, de naturaleza ficcional. El conocimiento, de esa manera, pierde la necesidad de buscar a toda costa una verdad y se concibe como algo vivo al interior del sujeto, en el entendido de que la experiencia que tenemos del mundo es diferente para cada uno de nosotros.

El factor de convergencia entre todas estas interpretaciones subjetivas de la realidad lo encontramos en el dialogismo; si bien es cierto que cada experiencia siempre recaerá en la esfera singular del individuo, también lo es el hecho de que esa manera "egoísta" de apropiarse del mundo se realiza sobre la base de una humanidad compartida, no en un sentido ideal o moral, sino en uno histórico.

Por último, en la literatura (en especial la de autoficción), praxis esencial de nuestra 
propuesta metodológica, el dialogismo, se da de manera espontánea, puesto que escribir y leer son acciones que obligan al Yo a salirse de sí mismo y buscar relaciones, tanto con su presente como con su pasado, e incluso con su futuro (Vilain, 2009).

\section{La realidad y la ficción son ámbitos especulares}

Es preciso señalar que realidad y ficción son categorías del pensamiento. Sus respectivos estatutos ontológicos son problemáticos en extremo. Nuestra experiencia de la realidad es extraña: por un lado, contamos con medios, nuestros sentidos, que no nos alcanzan para absorber toda la información contenida en el mundo externo, y por el otro, de manera un tanto desesperada, queremos llegar al fondo de las cosas, al entendimiento completo y cabal. De por sí ya somos una argamasa de razón y de ilusión, pero estaríamos muy equivocados si consideráramos esto un límite, es decir, algo que debemos superar para ser mejores de lo que somos. Nos preguntamos, de hecho, por qué los hombres de hoy siempre queremos ser mejores de lo que somos: ¿qué es lo que nos empuja hacia ese deseo? ¿Es porque estamos insatisfechos de nosotros o porque queremos alcanzar la dignidad y el prestigio de un supuesto autor único y eterno? Estas preguntas son también aquellas que se hace, en algún momento de su vida, cualquier artista.

La contradicción de la que hablamos es la que nos hace humanos. Por un lado, nos jalan las fuerzas demoniacas de la aniquilación, que nos hacen desconfiar de todo, nos introducen en el mundo del raciocinio y de la duda, y nos acercan a lo material y lo pragmático: al realismo, si queremos. Por el otro, los coros angélicos nos incitan a superarnos, a buscar la verdad, a crear, a imaginar, a acercarnos con fe y esperanza a la búsqueda de unidad. Todos terminamos siendo una mezcla de estas dos condiciones, las cuales luego concretamos en historias, poco importa si reales o ficticias (Alberca, 2007).

Ahora bien, en la sección anterior señalamos que la enseñanza debería consistir en construir, sobre esa capacidad que tenemos los hombres de asignar un sentido a las cosas (es decir, de vislumbrar una forma), una arquitectura propia y personal, que utilice incluso experiencias ficcionales de manera consciente. Como apunta Kundera (2009), la literatura nos hace partícipes de todos los aspectos de lo humano, por lo que escribir y leer se tornan una forma de experimentar ciertas condiciones espirituales, las cuales podemos trasladar a nuestras vidas reales. Aquí reposa el sentido de la autoficción: un modo reflexivo de verse estéticamente, más allá de la coincidencia entre nuestras experiencias de vida y cómo las consignamos al vacío de la página y, más en general, de la palabra.

La autoficción sería el contexto práctico en el que se desarrolla el sujeto estético. Las actitudes normales de quienes la practican son, en lo básico, dos: la ironía, por conducto de la cual estamos dispuestos a destruir nuestras creaciones y reírnos de nosotros mismos, y la fe, que nos lleva a no querer abandonar la esperanza de que exista una unidad de sentido eterna y protectora. Los contenidos de la autoficción son materiales de vida. El saber disciplinario es uno de ellos, es decir, se convierte en uno de los contenidos que el individuo puede utilizar para construir su personal arquitectura de sentido. Las disciplinas en sí no son perjudiciales, como es obvio, sino es su uso dentro de la enseñanza superior, en particular universitaria, que las convierte en un horizonte demasiado estrecho. Añadir el elemento ficcional a la construcción de la propia personalidad significa apostarle a una ciencia que no limita su alcance al 
solo estudio de la realidad, sino se abre a un mundo mucho mayor: el de las historias posibles (Feynman, 2006).

\section{CONCLUSIONES}

Para finalizar este trabajo, regresaremos a un asunto cuyo esclarecimiento juzgamos fundamental: una manera muy fácil de criticar estos bosquejos que presentamos hacia una metodología para la formación universitaria, sería la de afirmar que la adopción de un criterio estético en la constitución del individuo no asegura que este se comporte bien, pero ¿qué significa portarse bien? ¿A qué nos atenemos cuando queremos portarnos bien? Algunos a una moral, otros a una ética, otros más a un sistema de creencias (en un mercado tan vasto como el que hoy ofrece la globalización, cada uno puede vender su moral, su ética y su discurso prescriptivo, seguro de que habrá alguien, en medio de la selva oscura de la red digital, que los acogerá como propios). En otras palabras, nos portamos bien según una regla de comportamiento aceptada, que, sin embargo, trasgredimos con puntual alegría. Luego, imaginamos, algún Dios nos ofrecerá su hombro para sostenernos en el momento en que queramos deshacernos de la culpa por haber violado las reglas. Y así seguimos actuando, según un principio que cede la responsabilidad de nuestras acciones a otros. De ese modo, nos sentimos tranquilos, porque compartimos con alguien la vergüenza de nuestra mala conciencia. Y si somos tan necios al grado de que no dejamos de ampararnos detrás de nuestra buena conciencia, entonces seremos unos seres pasivos que no quieren aceptar la evidencia de lo contradictorio que es la vida.

Aquí apostamos por otra clase de responsabilidad: la del sujeto estético. La tesis es: la libertad estética implica una mayor responsabilidad que la libertad ética. Esto, por el hecho de que las leyes a las que nos sometemos cuando somos creadores (es decir, cuando nos creemos en pleno nuestro papel de autores) son las que hemos elegido nosotros, mientras que en la moral y la ética estas normas llevan un orden y un significado, que son el producto de la elaboración de otros (Rorty, 1995).

En este segundo caso, no se establece un vínculo directo entre la norma y la responsabilidad al interior del sujeto, porque ambas son externas. En un escenario como este, solo intervenimos como ejecutores materiales de un plan preestablecido. Y cuando nos hayamos cansado de uno, estaremos listos para seguir otro, y luego, otro más. Sin embargo, cuando somos conscientes de que nosotros tenemos un papel activo en nuestras decisiones, entonces la responsabilidad es inherente a lo que hemos creado, de modo que, si de leyes queremos hablar, estas serán de las más blandas, porque siempre tendrán que estar dispuestas a cambiar (esta sería, además, una definición muy paradójica de ley). Así, la responsabilidad de lo que hago será del todo mía: en y para mí (Dewey, 2014).

El horizonte disciplinario, cualquiera que sea, se torna un camino más fácil, aunque más seguro, para la formación, porque está basado en la fuerza externa de la tradición, hacia la que confluyen, además, muchos más intereses que los meramente académicos (Becher, 2001). La verdad, como se sabe, siempre está normalizada en el algún discurso (Foucault, 2002). En cambio, el camino de la creación es mucho más complicado, porque el sistema de reglas que necesitamos para brindar un sen- 
tido a las cosas lo tenemos que construir nosotros; eso, al mismo tiempo, nos convierte en los únicos responsables de nuestras creaciones, por lo que el principio de responsabilidad siempre estará asociado a una elección nuestra.

Pasamos a ser así los narradores de nuestra propia vida. El narrador, a diferencia del autor, quien se quiere instalar en la gracia eterna, es aquel que teje, entre enormes dificultades, la trama y se coloca a medio camino entre los sucesos de la vida (los materiales) y su manera de organizarlos (la forma). Sin embargo, no debemos olvidar que el narrador sigue siendo un personaje, puesto que se encuentra al interior de la representación. En pocas palabras, cuando escribimos, y también cada vez que hablamos, nos damos cuenta de que somos apenas una entre las muchas voces que componen el universo de nuestra autobiografía.

Al centro de nuestra propuesta se encuentra lo que podríamos llamar el "Yo narrativo", en cuyo marco la identidad y, por consiguiente, el conocimiento surgen de las circunstancias inmanentes al acto de narrar. De esta manera, el sujeto no solo es capaz de organizar, según sus necesidades, los materiales propios de su disciplina, sino que está en condición de profundizar muchos de los temas existenciales que pertenecen a las preguntas fundamentales sobre la vida y su papel en una sociedad compleja y plural.

\section{REFERENCIAS BIBLIOGRÁFICAS}

Acosta Silva, A. (2008). La autonomía universitaria en América Latina: problemas, desafíos y temas capitales. Universidades, vol. 36, pp. 69-82.

Agamben, G. (1988). El hombre sin contenido. Madrid: Árlea.

Alberca, M. (2007). El pacto ambiguo. De la novela autobiográfica a la autoficción. Madrid: Biblioteca Nueva.

Augé, M. (2003). Tiempos en ruinas. Barcelona: Editorial Gedisa.

Bajtín, M. (2012). Problemas de la poética de Dostoievski. Ciudad de México, México: Fondo de Cultura Económica.

Bajtín, M. (2005). La cultura popular en la Edad Media y el Renacimiento. El contexto de François Rabelais. Madrid, España: Alianza.

Bárcena, F. (2016). En busca de una educación perdida. Barcelona: Homo Sapiens Ediciones.

Barthes, R. (1987). La muerte de un autor. El susurro del lenguaje. Barcelona: Paidós.

Bateson, G. (1979). Mind and nature. A necessary unity. Nueva York: Dutton.

Beard, M. y Henderson, J. (2016). El mundo clásico. Madrid, España: Alianza Editorial.

Becher, T. (2001). Tribus y territorios académicos. La indagación intelectual y las culturas de las disciplinas. Madrid, España: Gedisa.

Beneitone, P., Esquetini, C., González, J., Marty Maletá, M., Siufi, G. y Wagenaar, R. (2007). Reflexiones y perspectivas de la educación superior en América Latina. Informe final. Proyecto Tuning-América Latina 2004-2007. Bilbao, España: Universidad de Deusto.

Bombini, G. (2009). La literatura en la escuela. En Maite Alvarado (coord.). Entre líneas: teorías y enfoques en la enseñanza de la escritura, la gramática y la 
literatura. Buenos Aires: Manantial.

Brockbank, A. y McGill, I. (2002). Aprendizaje reflexivo en la educación superior. Madrid, España: Morata.

Camarena Gómez, B. O. y Velarde Hernández, D. (2009). Educación superior y mercado laboral: vinculación y pertinencia social ¿Por qué? y ¿Para qué? Estudios Sociales, vol. 17, núm. 1, pp. 106-125.

Casalet, M. (2010). El tránsito de México hacia una economía basada en el conocimiento.Ide@s Concyteg, vol. 5, núm. 56, pp. 109-116.

Casassus, J. (2010). Las reformas basadas en estándares: un camino equivocado. Educere et educare. Revista de Educação, vol. 5, núm. 9, pp. 85107.

Castro Rodríguez, S. J. (2012). Ética y estética: una relación ineludible. Revista Latinoamericana de Bioética, vol. 12, núm. 1, pp. 63-69.

Cubero Vásquez, K. V. y Villanueva Monge, L. S. (2014). La evaluación cualitativa en el proceso enseñanza-aprendizaje como principio fundamental de una formación más humanista. Nuevo Humanismo, vol. 2, núm. 1, pp. 37-50: http://dx.doi.org/10.15359/rnh.2-1.3

Cuesta Abad, M. (1997). Las formas del sentido. Estudios de poética y hermenéutica. Madrid: Universidad Autónoma de Madrid.

De Garay, G. (coord.) (2013). Cuéntame tu vida. Historia oral: historias de vida. Ciudad de México, México: Instituto Mora.

De Vries, W. y Álvarez Mendiola, G. (2005). Acerca de las políticas, la política y otras complicaciones en la educación superior mexicana. Revista de la Educación Superior, vol. 34, núm. 2, pp. 81-105.

Dewey, J. (2014). Naturaleza humana y conducta: introducción a la psicología social. México: Fondo de Cultura Económica.

Dewey, J. (2008). El arte como experiencia. Barcelona, España: Paidós Ibérica.

Eco, U. (1981). Lector in fábula. Barcelona: Lumen.

Faix, D. (2013). La autoficción como teoría y su uso práctico en la enseñanza universitaria de la literatura. Actas del I Congreso Internacional de Didáctica de Español como Lengua Extranjera. Instituto Cervantes de Budapest. Recuperado de https://cvc.cervantes.es/ensenanza/biblioteca_ele/publicaciones_centros/PDF/budapest_2013/14_faix.pdf

Feynman, R. H. (2017). El placer de descubrir. Madrid: Crítica.

Feynman, R. H. (2006). Seis piezas fáciles. Madrid: Crítica.

Foucault, M. (2002). Vigilar y castigar. Madrid: Biblioteca Nueva.

Foucault, M. (1999). ¿Qué es un autor? Entre filosofía y literatura. Obras esenciales I. Barcelona, Paidós.

Fourez, G. (2006). La construcción del conocimiento científico. Sociología y ética de la ciencia. Madrid, España: Narcea Ediciones.

Freud, S. (1976). El Yo y el Ello. Buenos Aires, Argentina: Amorrortu.

Garay Sánchez, A. (2008). Los acuerdos de Bolonia; desafíos y respuestas por parte de los sistemas de educación superior e instituciones en Latinoamérica. Universidades, vol. 37, pp. 17-36.

García de la Sienra Pérez, R. (2015). Dialogismo, cultura y educación. Algunas consideraciones metodológicas. Estudios del Discurso, vol. 1, núm. 1, pp. 1-16. 
Gombrich, E. H., Hochberg, J. y Black, M. (2012). Arte, percepción y realidad. Barcelona: Paidós Estética.

Gould, S. J. (1989). La vida maravillosa: Burgess Shale y la naturaleza de la historia. Barcelona: Crítica.

Horkheimer, M. (1973). Crítica de la razón instrumental. Buenos Aires, Argentina: Editorial Sur.

Jacinto, C. (2004). Ante la polarización de oportunidades laborales de los jóvenes de América Latina. Un análisis de algunas propuestas recientes en la formación para el trabajo. En Claudia Jacinto (eds.). ¿Educar para qué trabajo? Discutiendo rumbos en América Latina (pp. 187-200). Buenos Aires, Argentina: La Crujía.

Kundera, M. (2009). Los testamentos traicionados. Ciudad de México, México: Tusquets Editores México.

Latour, B. (2008). Reensamblar lo social: una introducción a la teoría del actorred. Buenos Aires: Ediciones Manantial.

Levinas, E. (1995). De otro modo que ser o más allá de la esencia. Salamanca: Ediciones Sígueme.

Lukács, G. (1982). Estética I. Barcelona, España: Grijalbo.

Marrou, H. (2004). Historia de la educación en la antigüedad. Ciudad de México, México: Fondo de Cultura Económica.

Maturana, H. R. y Varela, F. G. (2003). El árbol del conocimiento. Las bases biológicas del entendimiento humano. Buenos Aires, Argentina: Lumen.

Meyer, J. W., Kamens, D. H. \& Benavot, A. (1992). School knowledge for the masses: World Models and national primary curricular categories in the twentieth century. Washington DC, EUA: The Falmer Press.

Monod, J. (2016). El azar y la necesidad: ensayo sobre la filosofía natural de la biología moderna. Barcelona: Tusquets.

Morin, E. (2010). Tierra-patria. Barcelona: Kairós.

Morin, E. (2001). La cabeza bien puesta. Repensar la reforma reformar el pensamiento. Buenos Aires, Argentina: Nueva Visión.

Morin, E. (1988). El método 3. El conocimiento del conocimiento. Madrid, España: Cátedra.

Musitano, J. (2016). La autoficción. Una aproximación teórica: entre la retórica de la memoria y la escritura de recuerdos. Acta Literaria, vol. 52, pp. 103-123.

Nietzsche, F. (1996). El viajero y su sombra. Madrid: Edaf.

Nietzsche, F. (1963). Sobre la verdad y mentira en sentido extramoral. Buenos Aires: Aguilar.

Pérez Ruiz, A. (2012). Desigualdad, mercado laboral y educación superior en América Latina. El Cotidiano, núm. 176, pp. 47-55.

Restrepo, L. (1994). El derecho a la ternura. Bogotá, Colombia: Arango Editores Ltda. Ricoeur, P. (2007). Tiempo y narración. Ciudad de México, México: Siglo XXI.

Ricoeur, P. (2006). Sí mismo como otro. Ciudad de México, México: Siglo XXI.

Rincón, O. (2006). Narrativas mediáticas. O cómo se cuenta la sociedad del entre- 
tenimiento. Barcelona, España: Gedisa.

Rorty, R. (1995). Consecuencias del pragmatismo. Madrid: Editorial Tecnos.

Rosenwald, G. C. y Ochberg, R. L. (1992). Storied lives: The cultural politics of selfunderstanding. New Haven, EU: Yale University Press.

Vilain, P. (2009). L'autofiction en théorie. París: Grasset.

Weller, J. (2003). La problemática inserción laboral de los y las jóvenes. Santiago de Chile, Chile: CEPAL.

White, H. (1992). Metahistoria. La imaginación histórica en la Europa del siglo $X I X$. Ciudad de México, México: Fondo de Cultura Económica. 